\title{
Risks of Fetal Tissue Donation to Women
}

\author{
Dorothy E. Vawter, Karen G. Gervais and Arthur L. Caplan \\ Center for Biomedical Ethics, University of Minnesota, Box 33 UMHC, \\ 420 Delaware St. S.E., Minneapolis, MN 55455, USA
}

Treating the aborted fetus as a human cadaver is believed to be justified because it is respectful and protective of the fetus. In the United States, most states permit the donation and procurement of human fetal tissue for educational, research, or therapeutic purposes in accord with the Uniform Anatomical Gift Act (UAGA). These state laws specify the protections necessary for the fetal cadaver and the circumstances under which the next-of-kin may donate its remains. However, treating the woman who agrees to donate fetal tissue merely as one of the next-of-kin who may consent to donate the tissue of her deceased relative is disrespectful and leaves her vulnerable to harm. It overlooks both the risks that donating fetal tissue pose to her as well as the unique relationship that exists between a woman and a fetus. The cadaver donor framework, for example, does not require the woman's consent before fetal tissue may be used; the consent of the father is considered sufficient. And, in any case, only minimal information is required to be disclosed to those deciding whether to donate the tissue of a deceased relative.

The following are possible risks to a woman's privacy and well-being associated with donating tissue for transplantation after elective abortion:

- Her blood may be tested for infectious agents such as HIV.

- The tissue may be labeled with an identifier that makes it possible to trace the woman who had the abortion and donated the tissue.

- Persons uninvolved in the woman's care may have access to her clinic records to obtain information about her medical history.

- The abortion procedure may be modified in ways that prolong or intensify discomfort, or that increase the risks of physical harm to the woman.

The living organ donor framework is more respectful and protective of the woman who is asked to donate fetal tissue than the cadaver donor framework. It acknowledges that the woman has a unique and privileged relationship with the fetus and that donation poses a variety of significant risks to the woman. Her respect and protection should be secured in the following ways:

- Her consent should be necessary; the father's consent should never be sufficient.

- She should be informed of the proposed use of the tissue.

- She should be informed of the risks that donation poses to her privacy. She should be informed of the risks associated with testing her blood or urine to establish the quality of the tissue, labeling the fetal tissue with an identifier traceable to her, and tissue procurers or others not directly involved in her care gaining access to private information in her clinic record.

- She should be informed of any modifications of the abortion procedure and the associated risks to her well-being. She should be informed of the risks of prolonged or intensified discomfort as well as the risks of incomplete abortion or trauma to the cervix associated with any modifications, e.g., slowing the abortion procedure, decreasing the pressure of the suction, or increasing the dilatation of the cervix and the cannula.

Neither the cadaver donor framework, nor the living organ donor framework, by itself captures the full range of obligations to both the fetus and the woman involved in fetal tissue transplantation. Combining these frameworks, however, so that they complement and constrain, rather than conflict with one another, will ensure that both the woman and the fetus are protected and respected. 

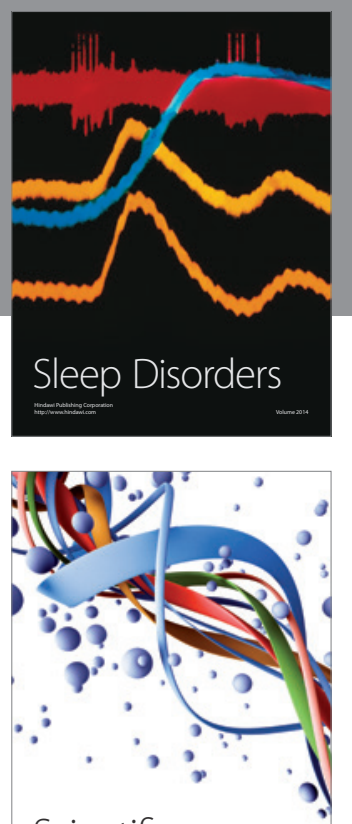

Scientifica
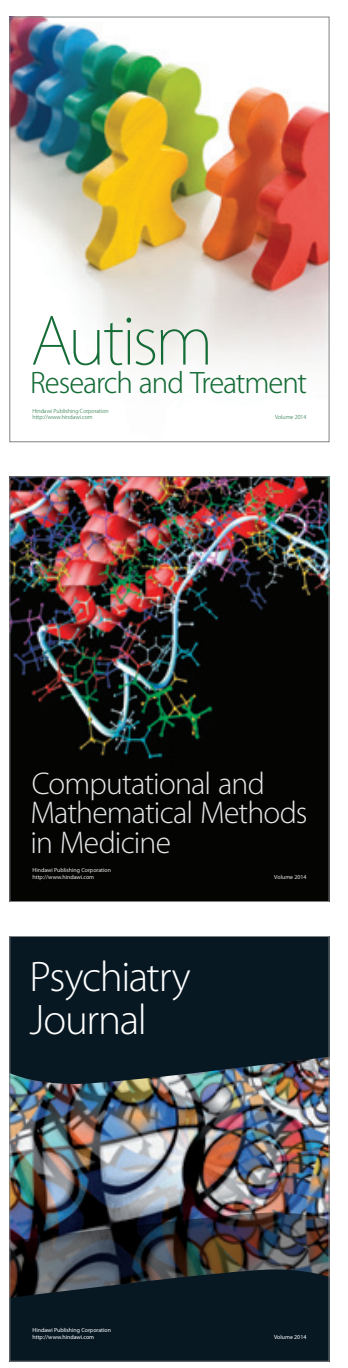
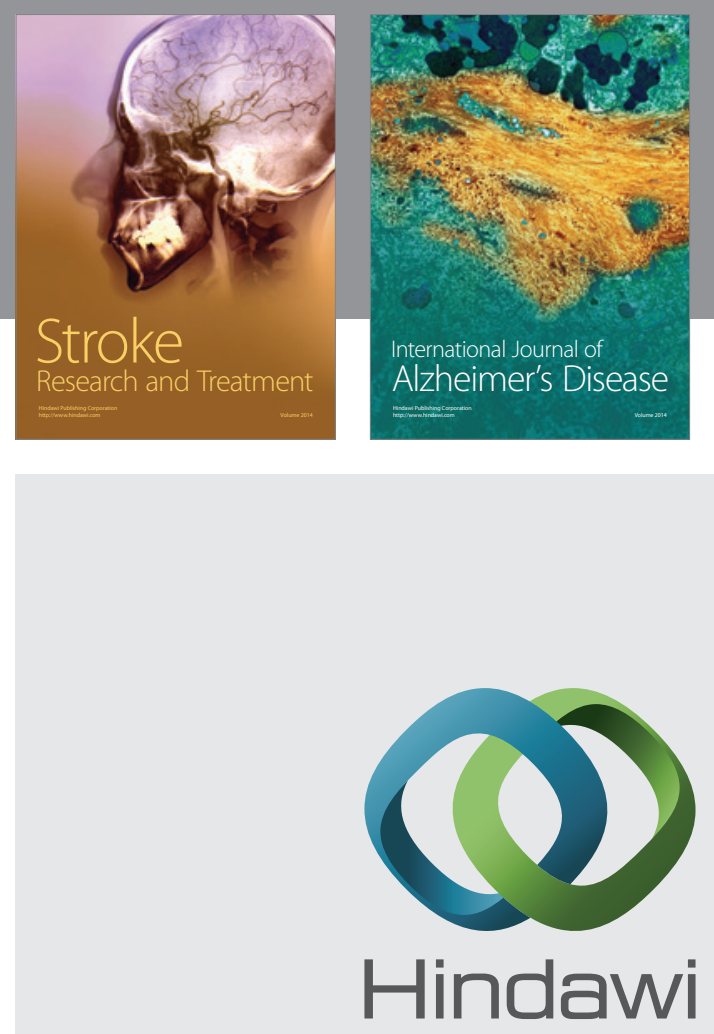

Submit your manuscripts at

http://www.hindawi.com
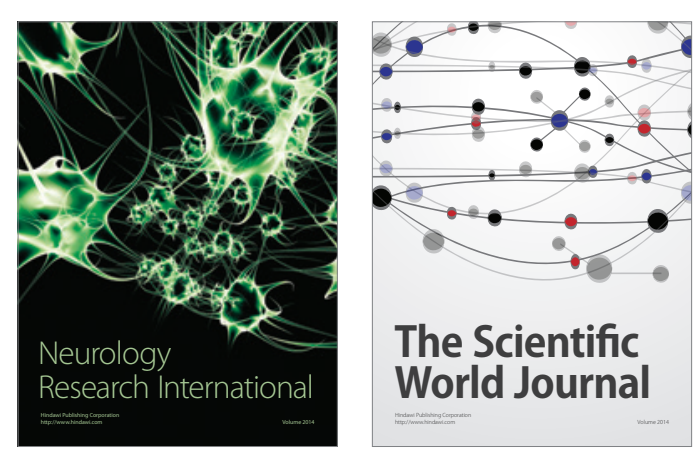

The Scientific World Journal

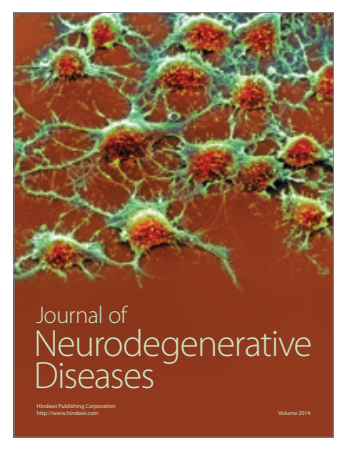

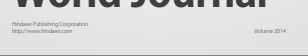

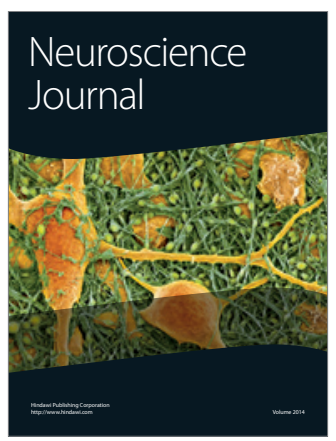

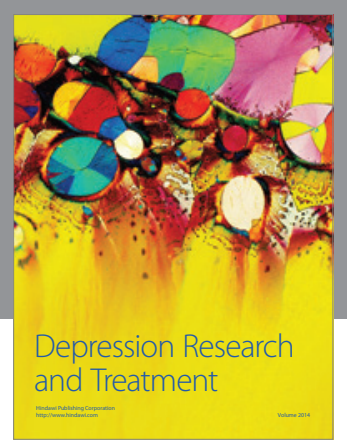
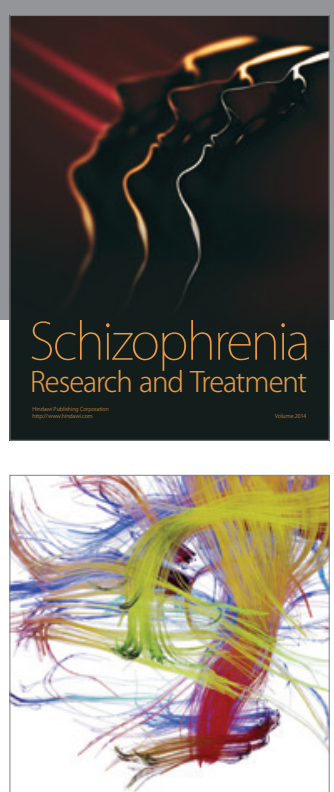

Brain Science

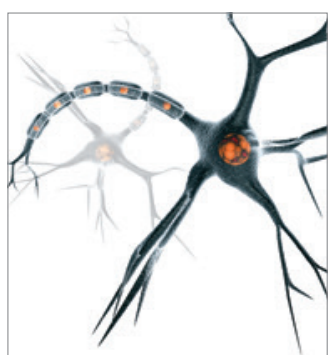

Neural Plasticity
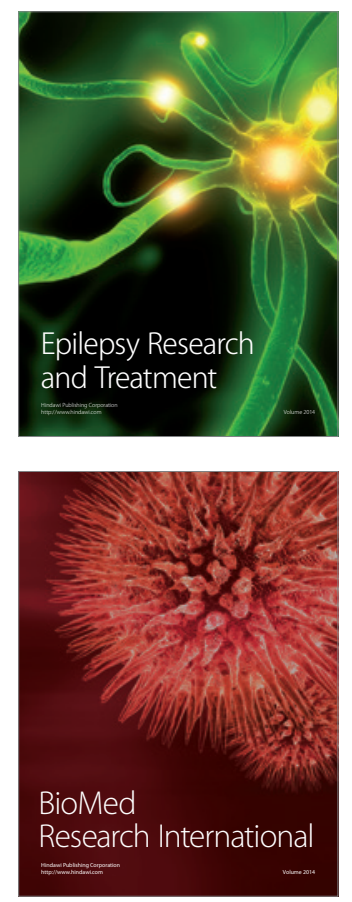

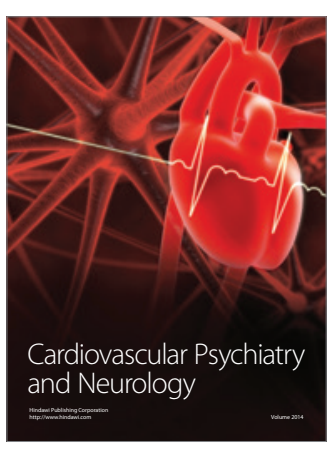

Parkinson's

Disease
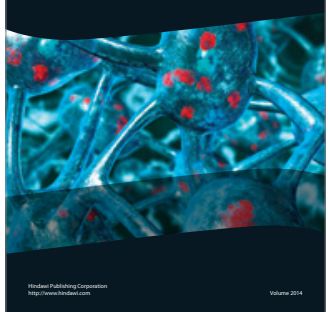